\title{
Protected areas in Central Mexico - are they fit in promoting species persistence under climate and land use changes?
}

\author{
Fernando Chacón-Prieto ${ }^{\mathrm{a}}$, Clarita Rodríguez-Soto ${ }^{\mathrm{b}}$, Angela P. Cuervo Robayo ${ }^{\mathrm{c}}$, \\ Julio César Carbajal Monroy ${ }^{\mathrm{d}}$, Diogo Alagador ${ }^{\mathrm{a}, *}$ \\ a The 'Rui Nabeiro' Biodiversity Chair, MED - Mediterranean Institute for Agriculture, Environment and Development, Universidade de Évora, 7000-890 Évora, Portugal \\ ${ }^{\mathrm{b}}$ Laboratorio Nacional de Observación de la Tierra, Facultad de Geografía, Universidad Autónoma del Estado México, Mariano Matamoros 1007, Ciudad Universitaria, \\ Toluca, Mexico \\ ${ }^{\mathrm{c}}$ Laboratorio de Biología Evolutiva, CIRB, Facultad de Ciencias, Universidad Autónoma del Estado de México, Toluca, Estado de México, Mexico

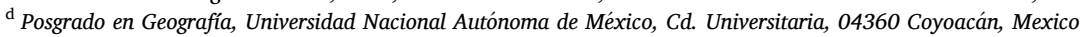

\section{A R T I C L E I N F O}

\section{Keywords:}

Connectivity

Conservation planning

Effectiveness

Niche models

Optimisation

UN's agenda 2030

\begin{abstract}
A B S T R A C T
Protected areas are among the most widely accepted methods to set aside biodiversity from their most impinging threats. However, protected areas are not always located such that their positive impacts over biodiversity are maximized. This drawback is especially significant and uncontrolled when intense climate-change dynamics stresses local biodiversity equilibrium. This study aims to weight plausible evolutive scenarios (up to 2040) of PA-effectiveness to secure the most suitable climates for 94 vertebrate species in Central Mexico, a region that, historically, has faced large biodiversity turnover rates. Effectiveness was appraised at two scales. For a set of species, effectiveness expresses the spatial matching of established protected areas (ePAs) with top priority areas (T17) obtained from an optmised area-selection protocol. For each single species, effectiveness relates the predicted trends of climate suitable areas within ePAs/T17 with trends outside ePAs/T17. Results show that aprox.54\% of ePAs area occur within T17 and species present variable responses, with suitability gains up to $10 \%$ and potential climate suitability losses of aprox.30\% within ePAs. A considerable high amount of T17 (aprox.74\%) is left unprotected. By assuming the high-valued component of past conservation efforts, this study delivers a double-guidance for planners and decision-makers. First, it pinpoints the ePAs that will demand further conservation investments in the upcoming years. Second, it identifies the unprotected regions where most active conservation actions are needed to supplement ePAs for a climate-effective protected area network. The framework here-proposed gives decision-makers the means to undertake effective and robust decisions in a dynamic and uncertain world.
\end{abstract}

\section{Introduction}

Since the end of World War II, biodiversity conservation efforts have been raising worldwide (Le Saout et al., 2013; Juffe-Bignoli et al., 2014). By setting aside biodiversity from local threats (i.e., overexploitation, habitat loss, human presence), protected areas (PAs) have emerged as key conservation instruments with the aim of promoting adequate conditions for biodiversity to persist at long-term (Rojas, 1992; Le Saout et al., 2013). However, the short budgets that are, typically, available for conservation actions (Coad et al., 2019) and the way PAs have been assigned (i.e., mainly through political decisions without scientific guidance) makes them unlikely to buffer biodiversity from their contextual threats (Loucks et al., 2008; Joppa and Pfaff, 2009; Baldi et al., 2017) and consequently, unprepared to counteract large-scale emerging threats like climate change (Hannah et al. 2002; Araújo et al., 2004; Hannah, 2008; Araújo et al., 2011).

Systematic Conservation Planning (SCP) provides a framework to support planners and decision-makers to undertake actions under scientifically-informed guidelines (Margules and Pressey, 2000) and therefore to take the largest ecological benefits from their (typically scarce) budgets. Among others, SCP enables questions like "where PAs should be located to give the highest benefits per dollar spent?" and "how effective are already-established protected areas (ePAs) in safeguarding biodiversity from their major threats?" to be responded with

\footnotetext{
* Corresponding author.

E-mail address: alagador@uevora.pt (D. Alagador).
} 
the use of analytical, transparent and optimised approaches. Among these, bioclimatic niche models (BNMs) and spatial conservation planning software emerge as pivotal tools to obtain predictions about ecological and socio-economic processes through space and time and to deliver optimised area-prioritisation maps for complex and non-trivial decision-making problems like the ones typically characterizing longterm spatially-explicit conservation plans (Ackerly et al., 2010; Faleiro et al., 2013; Loyola et al., 2014). Conservation studies that explicitly anticipate the consequences of projected environmental and socioeconomic dynamics are decisive in providing the backbones for an effective, fully functional, PA network to secure key biodiversity elements and processes at long-term (Costello and Polasky, 2004; Strange et al., 2006; Alagador, 2021).

Several studies have evoked the pervasiveness of ePA in failing to cover the most critical areas for species to persist (Araújo et al., 2011; Johnston et al., 2013; Leach et al., 2013; Gillingham et al., 2015; Thomas and Gillingham, 2015). However, these failures do not imply that long-term ecological value in ePAs do not exist and that past efforts are entirely worthless. For example, ePAs may: (a) support climateadaptive species range shifts, as core or transition areas (Thomas and Gillingham, 2015); (b) provide suitable areas for novel conservationconcerning species to be established in the planning region (Berteaux et al., 2018); (c) deliver small scaled biotic and abiotic features serving as micro-refugia, where contextual evolutionary pressures may operate, thus leading to new genetic signatures (Michalak et al., 2018); (d) be appealing laboratories to conduct controlled scientific studies and to be used as experimental centers for testing new conservation approaches, (e) be used as readily-available areas to gather evidence on ecological processes and monitoring (Gstaettner et al., 2018); (f) define validation centers, where analytic expectations are contrasted with the realised states (McCarthy and Possingham, 2007; Gaston et al., 2008); and (g) provide context for development of local education and communication programs (Beaumont and Dredge, 2010; Van Vleet et al., 2016). Consequently, there is still potential for ePAs to serve as "seeding-areas" from which new complementary areas are defined to increase long-term effectiveness of the whole PA network with the least financial investments (Alagador and Cerdeira, 2007).

Mexico is in a transition zone between two main bioregions in America (Nearctic and Neotropical) and has served as an important passage area for many species during the Great American Interchange (Escalante et al., 2004; Pelegrin et al., 2018). As a consequence of its strategic position, many species find their northernmost and the southernmost range limits in Mexico (Morrone et al., 2017). In this context, Mexico ranks high in species and habitat richness, endemism (Ceballos, 2008) and, consequently, it is part of several global conservation schemes (Brooks et al., 2006). Agriculture and forestry are the main socio-economic activities in the region and are major drivers of habitat loss and fragmentation, largely impacting the species already stressed by climate change. To counter-back these negative outcomes, in the last decades Mexico governments have created 176 PAs covering close to $13 \%$ of the national territory (Ceballos et al., 2009). Following global standards, these PAs were established assuming environmental stability and, therefore, neglect the effects of both natural and anthropic dynamics, leaving them exposed to the risks of ineffectiveness (Botello et al., 2015; Cantu et al., 2004a; Cantu et al., 2004b; Esperon-Rodriguez et al., 2019; Fuller et al., 2007; Ortega Huerta, 2007; Sieck et al., 2011).

In this study, we present a comprehensive assessment to evaluate the performance and supplementary areal requirements of ePAs, in Central Mexico (CM), Mexico, in assisting the persistence of 94 vertebrate species from a baseline time period (2009) to 2040, under two plausible scenarios of climate and land-use change. Analysis is particularly focused in the Mexican State as, in the last decades, governments have undertaken a massive expansion of ePAs (of various protective typologies) reaching, at present-time, approximately $50 \%$ of the state's area. However, the region is still intensively covered by agriculture, livestock and forest industries, making it exposed to the interactive threats of climate change and habitat loss and fragmentation (Moreno-Barajas et al., 2019). Under this context, we aim to: (a) evaluate the representativeness of ePAs within optimised sets of top-priority areas, obtained after running spatial prioritisation models using varying levels of climate and land-use dynamics, species' priority templates and species' dispersal scenarios; (b) comparatively assess species-specific trends on the availability of suitable climates within ePAs and top-priority areas against trends of climate suitability in the whole region, and; (c) identify the areas that complement ePAs in acomplishing the maximum effectiveness in the region (i.e., maximise species' persistence).

We trust that the scientific-based approach here considered may be used to assist planners and decision-makers on where to invest, to secure local biodiversity from the expected impacts of climate and land-use changes. By explicitly reducing the inherent conflicts between conservation goals and the most typical socio-economic demands, our results demonstrate that opportunity-windows for a modern vision on biodiversity exist and need to be explored, such that, in the upcoming years, elemental pieces of functional ecosystems are maintained and secured (General Assemly UN, 2015).

\section{Materials and methods}

\subsection{The study area and the species}

The study area is located in Central Mexico, in the transition between "temperate sierras" and tropical dry forest. It encompasses a rich diversity of physical, biological and social attributes (Ceballos et al., 2009), which are nowadays threatened by the rapid expansion of agriculture and forestry practices. For analytical purposes, CM is here defined by the geographic window $18.09^{\circ} \mathrm{N}$ to $20.56^{\circ} \mathrm{N}$ and $100.94^{\circ} \mathrm{E}$ to $98.30^{\circ} \mathrm{E}$, which is centred in Mexico State and includes parts of the neighboring states, namely Querétaro and Hidalgo in the north, Morelos and Guerrero in the south; Michoacán westwards and eastwards Tlaxcala, Puebla and Mexico city. This whole region accommodates the densest human populations in Mexico and is, therefore, largely exposed to anthropic pressures. The region was partitioned in 93,832 grid-cells, defining planning-units of $1 \mathrm{~km} \times 1 \mathrm{~km}$ size (see Fig. S1 in Supplementary Material).

Analyses were made for 94 species (10 amphibians, 13 reptiles, 50 birds and 21 mammals), which were selected based on a set of conservation-based criteria: (a) conservation status in global/ regional listings (e.g., List of priority species and populations in Mexico: SEMARNAT, 2010; the IUCN Red List; Convention on International Trade in Endangered Species); (b) availability of comprehensive spatial data on species' occurrences (GBIF, 2016, https://www.gob.mx/conabio); (c) reported distribution ranges (www.naturalista.mx; www.gob. $\mathrm{mx}$ /conabio) and (d) levels of endemism estimated from species' distributional patterns (SEMARNAT, 2010; NaturaLista: www. naturalista.mx/) (Table S1). Georeferenced occurrence data (cumulative records from 1960 to 2015) for the studied species were obtained for the whole Mexican territory and point records were matched to the 1 $\mathrm{km} \times 1 \mathrm{~km}$ grid cell, with records of a species in a cell being assigned as an occurrence. In the end, species' occurrences ranged from 900 to 140,000 grid cells.

\subsection{Bioclimatic niche models}

We used bioclimatic niche models (BNMs) to estimate speciesspecific averaged environmental suitability in the baseline time period (1979-2009) and for 2015-2039 (here referenced as 2040), under two contrasting and plausible climate and land-use scenarios, developed under the 5th Assessment Report of the Intergovernmental Panel on Climate Change (RCP4.5 and RCP8.5, representing middle and large rates of change, respectively, Bernstein et al., 2008).

Climate data were derived from Cuervo-Robayo et al. (2014) and comprise a regional upgrade of the 19 WorldClim bioclimatic variables 
(Hijmans et al., 2005) (Table S2). Local contextual topographic features were used to derive downscaled predictions from GCM data into the region, thus providing more accurate assessments when compared to the general statistical downscaling techniques available from WordClim. Climatic projections for 2040 were downloaded from the National Ecology and Climate Change Institute of Mexico (www.gob.mx/inecc/). Land-use information for the baseline period was obtained as a cartographic product identified as "SERIE V" from the National Institute of Statistics, Geography and Informatics (www.inegi.org.mx/, Inegi, 2013). It comprises seven land-use/cover classes: urban areas, agriculture, tropical forest, tempered forest, shrubs, grasslands and other types of vegetation less prevalent (Durán et al., 2011). For simplification, land-use/cover will be named land-use, hereafter. Climate and land use data were used at their original $1 \mathrm{~km} \times 1 \mathrm{~km}$ resolution (Table S2).

The most explicative variables regarding species' occurrence patterns in the whole Mexico country were identified for each species using a variable selection approach. For each species the whole set of bioclimatic and land-use variables were tested using generalized linear models (GLM, using a logit link function) through the R package glmulti (Calcagno and de Mazancourt, 2010) (Table S3). The most parsimonious additive variable subsets were obtained finding the sets of five to ten predictor variables entangling the largest information from the modelled relationships. In our analyses the sets of variables with the lowest Bayesian Information Criterion values were selected (Franklin, 2010). Size reduction on predictors avoids model overfitting and increases transferability performance (Merow et al., 2014). These subsets were used to calibrate BNMs at $1 \mathrm{~km} \times 1 \mathrm{~km}$ for the whole Mexico. Eight distinct model-types were selected within the biomod2 R-package (Thuiller et al., 2016) (GLM; generalized additive models; artificial neuronal networks; flexible discriminant analysis; classification and

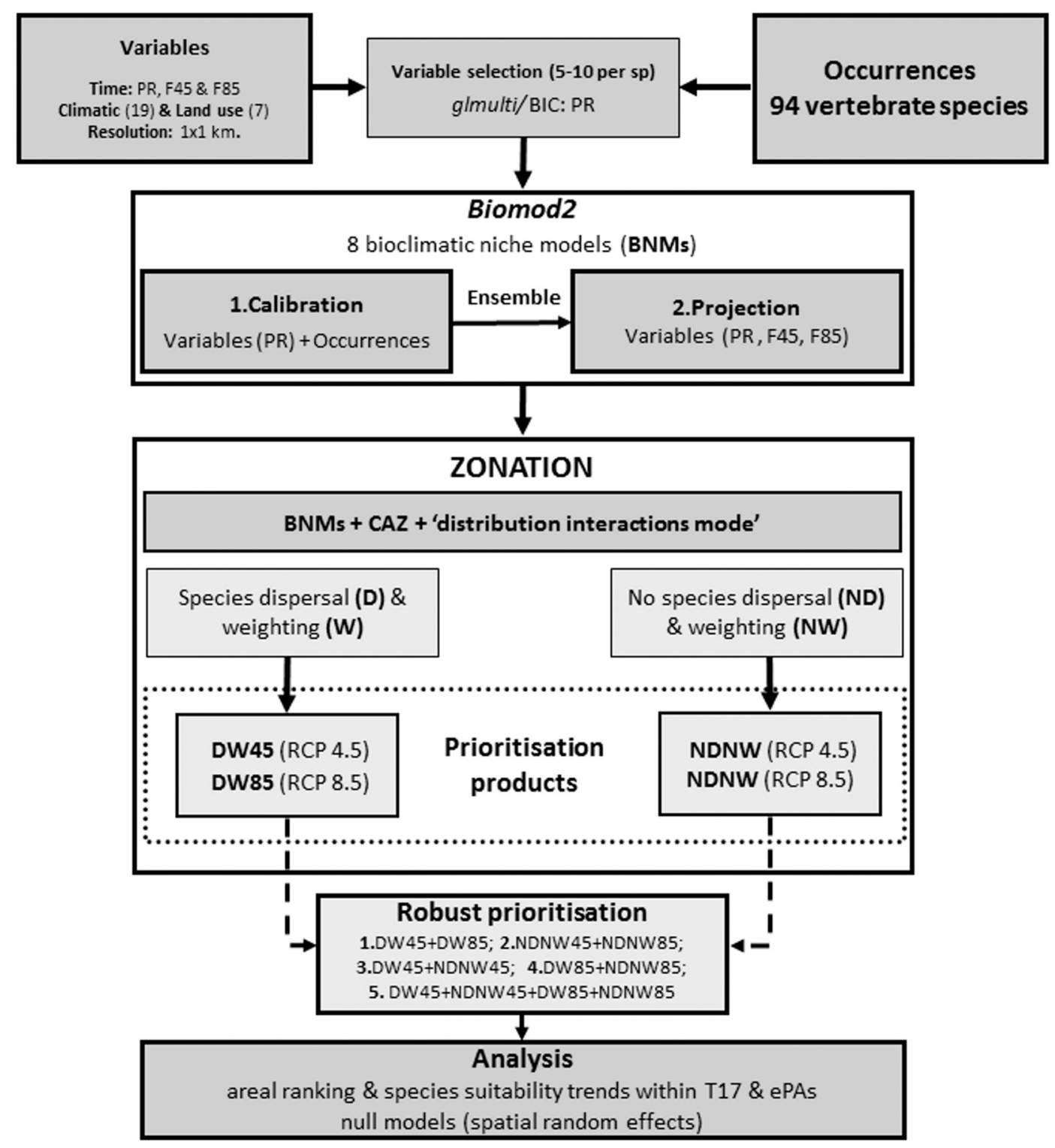

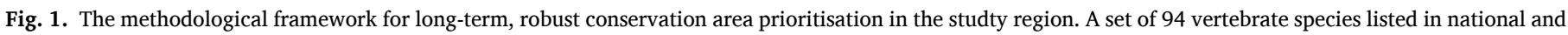

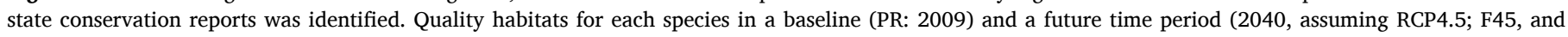

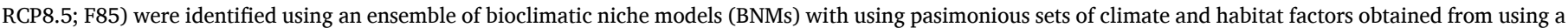

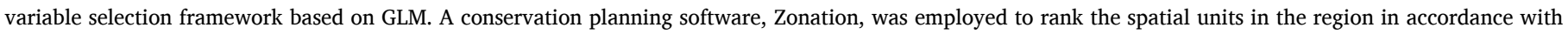

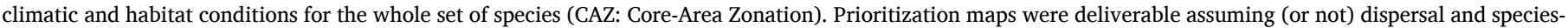

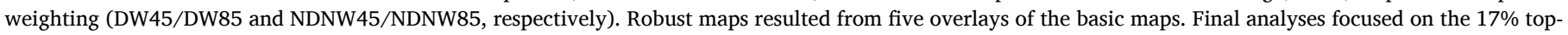

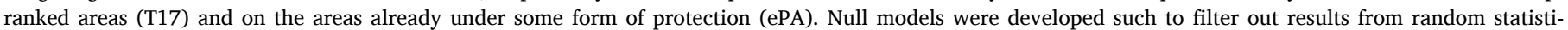
cal effects. 
regression tree analysis; surface range envelope; generalized boosting models and maximum entropy models, MaxEnt). For each species, ten sets of 1000 absences (or background grid cells, depending on model type) were randomly generated in the region (Barbet-Massin et al., 2012) and, for each set, five cross validation procedures $(70 \% / 30 \%$ calibration/validation data) were performed. Model accuracy was evaluated using the True Skill Statistic (TSS, Allouche et al., 2006) (Table S4).

Models were re-projected into the $1 \mathrm{~km} \times 1 \mathrm{~km}$ grid cell of the study area, for the baseline-period (2010: PR) and 2040 (RCP4.5: F45; RCP8.5: F85), using a TSS-weighted average among the outputs from the eight model-types (Araújo and New, 2007; Nori et al., 2016).

\subsection{Area prioritisation}

We used the spatial conservation planning software Zonation (Moilanen et al., 2014) to rank grid cells according to their environmental suitability for the whole set of targeted species, both in the baseline and future time periods. Prioritisations were made using the "core-area algorithm", as it ranks highest the areas with the largest suitability scores for each species in the time periods assessed (Moilanen et al., 2014). Climate change effects were integrated using the "distribution interaction" procedure, to define high-suitable regions in 2040 that are accessible from high-suitable areas in baseline period, given species' dispersal abilities. In order to Zonation's outputs be robust to the varying BNM predictions, a cost layer was produced using the largest coefficient of variation taken from the eight suitability predictions among the assessed species (i.e., Assuming two grid cells with the same suitability scoring, priority is given to the one with the lowest variability) (Figs. S9 \& S10). Finally, urban areas were removed from the analysis, given that, at the scale of analysis, they do not offer "quality habitats" for biodiversity conservation (Fig. 1).

Sensitivity of priority maps to two additional factors were tested. First, species' dispersal rates $(\mathrm{km} / \mathrm{yr})$ were obtained using the allometric relationships presented in Warren et al. (2013) and Zhu et al. (2015). Second, we undertook Principal Component Analysis (PCA) over a set of important factors which relate both to the exposure and the vulnerability of species to climate and land-use changes: (a) adult body size (Injeti and Kumar, 2013; Hamer et al., 2015); (b) conservation statuses (Rodríguez-Soto et al., 2017), (c) endemicity, according to NOM-059SEMARNAT, (d) a rarity index based on availability of suitable environments $\left(r_{s}\right)$ at the baseline period in the region $\left(\sum_{i \in M} s t_{s}^{i, p r e s}\right.$, where $M$ is the whole set of grid-cells in the region and $s t_{s}^{i, p r e s}$ refers to the suitability score of grid-cell $i$ for species $s$ at present-time. We recorded the linear combination defined by the first two PCA axes (explaining aprox. $70 \%$ of data variability) and we sorted these scores among species. Species prioritisation weights were settled using these PCA scores, such that the largest scores correspond to the species with largest conservation demands, the largest endemicity and the lowest range size and suitable area available (Table S5).

For each future scenario (RCP4.5 and RCP8.5), we also obtained two different prioritisation maps built from combinations on choices about species' dispersal data (dispersal, D, and no-dispersal, ND) and speciesweighting schemes (differential weighting, $\mathrm{W}$ and uniform weighting, NW): DW45, NDNW45; DW85; NDNW85.

In order to identify robust solutions to climate, dispersal and species weighting factors, we produced three types of consensus maps from the four basic maps above, by summing grid cell ranks of: (a) DW and NDNW maps for each RCP, mer45 and mer85; (b) the two RCP-based maps for each parameterization option (merDW and merNDNW), and (c) all four basic mappings into one map (merALL) (Fig. S2), followed by $0-1$ standardization of each map.

\subsection{The established protected areas and the top-priority areas}

The boundaries of the ePAs in the region were obtained from 2014 report of the National Commission for the Knowledge and Use of Biodiversity, CONABIO (http://www.conabio.gob.mx/informacio $\mathrm{n} / \mathrm{gis} /$ ) and were matched with the $1 \mathrm{~km} \times 1 \mathrm{~km}$ grid cells, such that grid cells with $0.5 \mathrm{sq}-\mathrm{km}$ or more of ePAs were assumed protected (Fig. S1).

While Zonation retrieves a ranking for the whole region, we centred our analyses on the top 17\% ranked grid cells (T17), as it quantitatively matches the CBD Aichi Target 11 (Woodley et al., 2012; Leadley et al., 2014; Juffe-Bignoli et al., 2014; Tittensor et al., 2014).

\subsection{Analyses}

\subsubsection{Rank differences among maps}

We estimated the similarity between the distinct maps generated with varying dispersal and species weighting templates and climate/ land-use expectations. We undertook Wilcoxon signed-ranked tests to evaluate the significance of pairwise rank differences among the basic and merged prioritisation maps and we measured the effect size of rank differences using the Mann-Whitney U-statistic (Table S6). Among all possible grid cell pairings between two maps, the U-statistic estimates the expected number of grid cells in one prioritisation map with larger rank scores than grid cell scores in the comparing map (Hart, 2001). Additionally, we mapped rank differences resulting from dispersal rate and species weighting choices $\left(\Delta_{p a r}=\right.$ merDW - merNDNW) and climate scenario $\left(\Delta_{\text {clim }}=\right.$ mer45 - mer85), thus allowing the regions more exposed to uncertainty to be highlighted.

\subsubsection{Matching ePAs and $T 17$}

We conducted three tests to evaluate the functional value of ePAs. First, we obtained the amount-area of ePAs overlapping the optimised set of top-priority areas (T17) obtained in the distinct maps.

Second, we tested whether the amount overlap of ePAs and T17 is, or is not, a random by-product of area displacements in the two sets. We therefore compared the ePAs/T17 overlap obtained in the distinct mappings with the overlaps obtained after defining T17 sets after 1000 permutations of grid cell ranks in the whole study-region. We assumed significant deviances from a random process if the measured overlaps were either in the $5 \%$ smallest or $5 \%$ largest permutated overlap values (see, Alagador and Cerdeira, 2007, for an algebraic derivation of the test).

Finally, similar to the previous analysis but focusing on ePAs rank scores, we appraised if the ranks-sums of ePAs cells in T17 are, or not, significantly larger (or smaller) than rank-sums of ePAs obtained in new T17 sets defined after 1000 permutations of rank-values in the whole study region.

The unprotected areas obtained in the T17 area sets for the distinct parameterisations and climate/land-use scenarios are likely to be relevant for protection, as they are seemed to complement ePAs in defining a robust (i.e., uncertainty-proof) PA network with the maximum persistence perspectives of the analysed species up to 2040, under plausible scenarios of change.

\subsubsection{Predicted trends of environmental suitability in ePAs and $T 17$}

We quantified the effectiveness of ePAs and T17 area-sets in capturing the environmental (i.e., climatic and land-use) suitability of each of the species in each prioritisation map for, both, the baseline and future time periods (RCP4.5 and RCP8.5). For each species, $j$, we recorded, the sum of suitability scores in each area-set (absolute suitability index, $S_{j, a b s}$ ) and the fraction of the summed species suitability in the whole region within the area-sets (relative suitability index, $S_{j, \text { rel }}$ ). We then assessed present to future trends in absolute $\left(\Delta S_{j, a b s}\right)$ and relative suitability scores $\left(\Delta S_{j, r e l}\right)$ in T17 and ePAs:

$\Delta S_{j, a b s}=\sum_{i \in M^{\prime}}\left(\frac{s t_{j}^{i . j u t}-s t_{j}^{i, \text { base }}}{s t_{j}^{i, \text { base }}}\right)$, 
$\Delta S_{j, \text { rel }}=\frac{\sum_{i \in M^{\prime}}\left(s t_{j}^{i, f u t}\right)}{\sum_{i \in M}\left(s t_{j}^{i, f u t}\right)}-\frac{\sum_{i \in M^{\prime}}\left(s t_{j}^{i \text {,base }}\right)}{\sum_{i \in M}\left(s t_{j}^{i, \text { base }}\right)}$,

where $M^{\prime}$ is either T17 or ePAs, $M$ defines the whole study area and $s t_{j}^{i p r e s}$ and $s t_{j}^{i}$, fut refer to the suitability scores of species $j$ in grid cell $i$ at the baseline and future time periods, respectively. Values of $\Delta S_{j, a b s}$ vary between -1 and infinite, with negative values indicating loss of suitable area in $M^{\prime}$ in the future. Values of $\Delta S_{j, \text { rel }}$ vary between -1 and 1 , with negative scores indicating a loss of suitability in $M^{\prime}$ in future-time. Importantly, the losses indicated by $\Delta S_{j, \text { rel }}$ may result from either, a larger loss of accumulated suitability inside $M^{\prime}$ when compared to the overall region, or from an increase of suitability in $M^{\prime}$ but at a smaller rate than suitability gain in the whole region.

Finally, current-to-future absolute and relative suitability trends for each species were obtained in 1000 maps made after permutations of grid cell ranks. Again, the $5 \%$ and $95 \%$ percentiles within the distributions of suitability scores were defined as thresholds of significance against a random expectation.

\section{Results}

\subsection{Area prioritisation maps}

All obtained maps with varying species-based parameterisations and climate/land-use scenarios presented similar prioritisation patterns (Figs. S3 and S4), with the top-priority sites (T17) located in the central part of the study region, as well as in neighboring states (Hidalgo, Puebla, Guerrero, and Michoacán). Most importantly, half of the priority sites (T17) overlapped with ePAs (Fig. S5).

In general, pairwise comparisions of rank values in the distinct mapping products (i.e., four base maps and five consensus maps) did not depict significant dissimilarities (Table S6). Rank differences concerning the two species based parameterisations used for area prioritisation (ND versus NWND) were larger than the rank differences obtained from the two climate/land-use scenarios analysed (RCP4.5 versus RCP8.5), i.e., in general, among the whole region $\Delta_{\text {par }}>\Delta_{\text {clim }}$ (see Fig. S6, in particular the rank differences in $\mathrm{T} 17$ regions).

Prioritisation ranks of ePAs locations presented a bimodal rankdistribution, with peaks on areas of low conservation value and in the top-priority T17 areas (Figs. 2; S8). Moreover, the representativeness of T17 in ePAs was larger than 95\% of the random T17 tested (Fig. S7). In average, among the distinct set of maps, $54 \%$ of T17 area matched ePAs, while $61 \%$ of ePAs overlapped T17 areas. We also found that among the whole ePAs-unprotected grid cell pairings, in an average of $61 \%$ (U = 0.611), rank scores of ePAs were larger.

\subsection{Species suitability analysis}

In general, the two assessed RCPs delivered presented similar trajectories of species-specific environmental suitability $\left(\Delta S_{\text {, abs }}\right.$ and $\left.\Delta S_{j, r e l}\right)$ within ePAs and T17 (Fig. 3, Tables S7 and S8).

The environmental suitability inside ePA will increase for 70 species (in average), with some species presenting up to 10 -fold suitability expansions. However, for most of these species, the suitability gains in ePAs did not follow the larger increases expected for the whole region (i. e., $\Delta S_{j, \text { rel }}<0$ ). For 16 of these species the negative trends in relative suitability inside ePAs are likely to be worst when compared with suitability trajectories in random areas of similar size. Conversely, for 33 species, the fraction of environmental suitability inside ePAs is expected to increase more than in (at least) $95 \%$ of randomly equal-sized area sets in the region.

Similar patterns occurred when testing suitability trends within T17 priority-areas. Fifty species exhibited higher suitability gains in T17 when compared to suitability evolution among the whole region (i.e., $\Delta S_{j, \text { rel }}>0$ ) For $26 / 28$ species, suitability trends in T17 showed larger increases/ decreases than expected by chance (see Table S9, for a list of species presenting the largest gains and losses in ePAs and T17).

\section{Discussion}

Important amounts of resources have been invested for the settlement of PAs worldwide (McCarthy et al., 2012; Geldmann et al., 2019) but, to what level are they effective in promoting biodiversity conservation at medium- to long-terms? Here we try to respond to this question for a region in Mexico, the CM, under a context in which the widespread concerns about the impacts of global changes and the alarms of intense and pervasive use of lands for unsustainable socio-economic development require a conceptual revolution on biodiversity conservation policies (Hannah et al., 2002), namely with the use of cutting-edge analytic frameworks explicitly designed to maximise cost-effectiveness under dynamic environmental and political contexts.

The CM is inserted within a region that has experienced in the past large biodiversity turn-overs (e.g., the Great American Interchange, approximately 2.5Myr ago) (Schubert et al., 2019). Because those dynamic pulses are still imprinted in the genetic pools of species (Johnstone et al., 2016), it could be argued that local biota is well prepared to
A

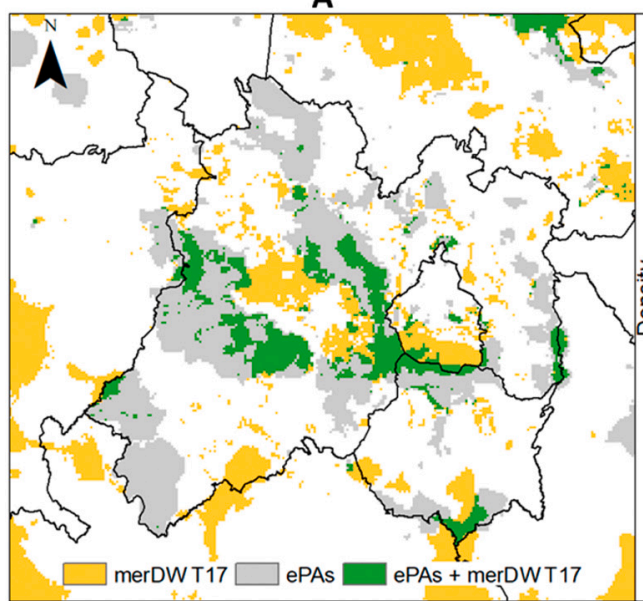

B

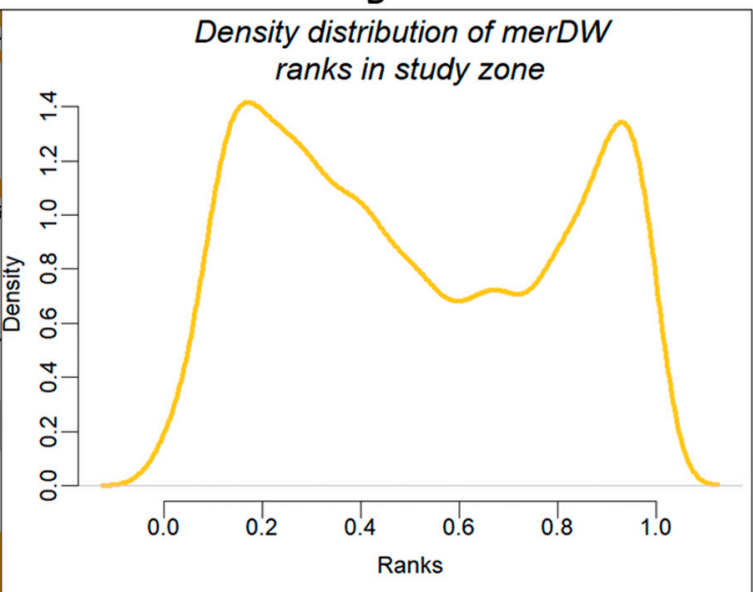

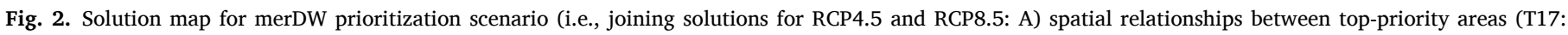

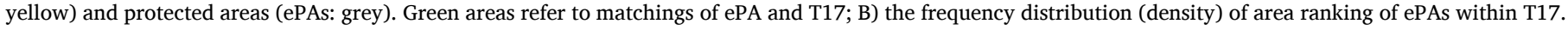
(For interpretation of the references to colour in this figure legend, the reader is referred to the web version of this article.) 
A

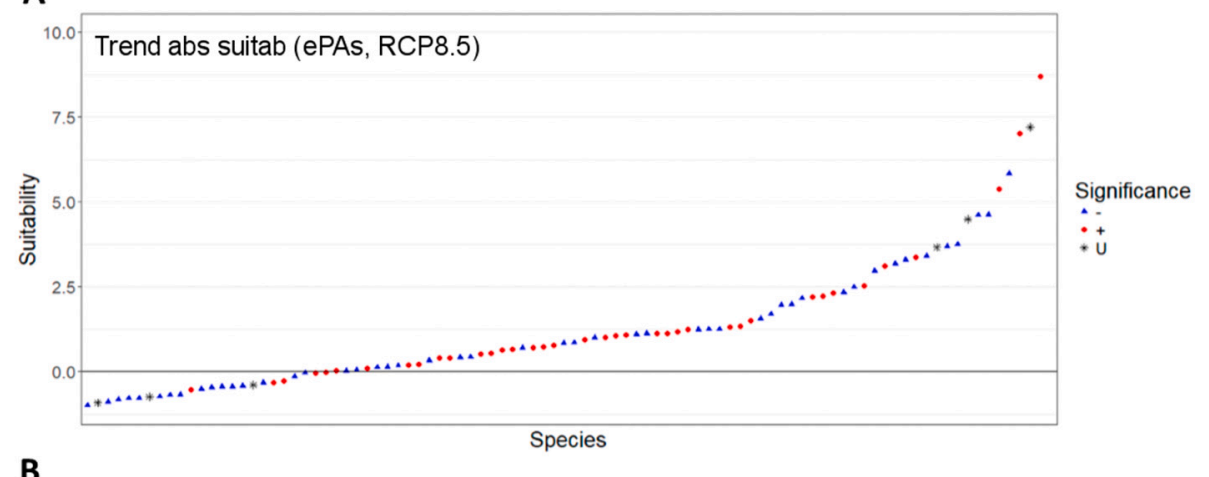

B

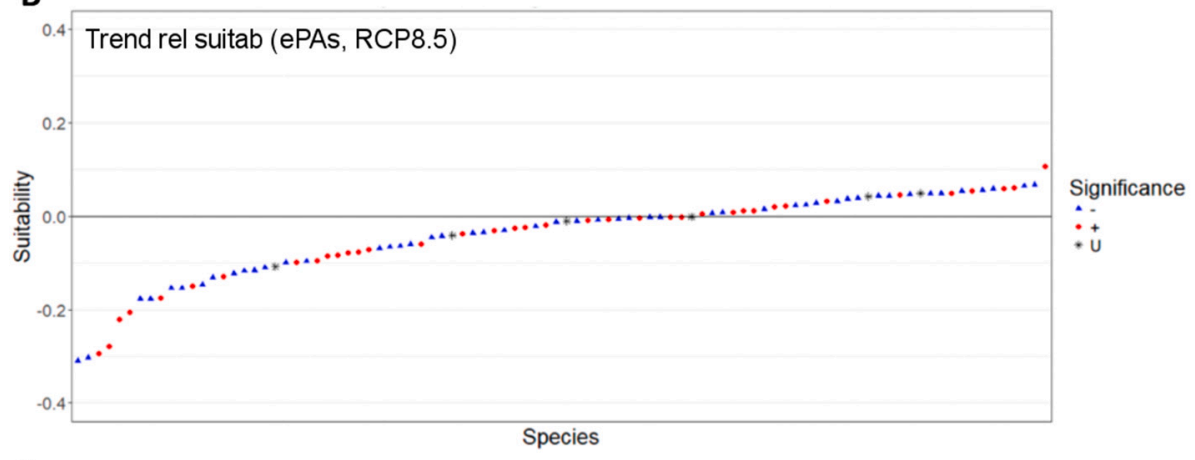

C

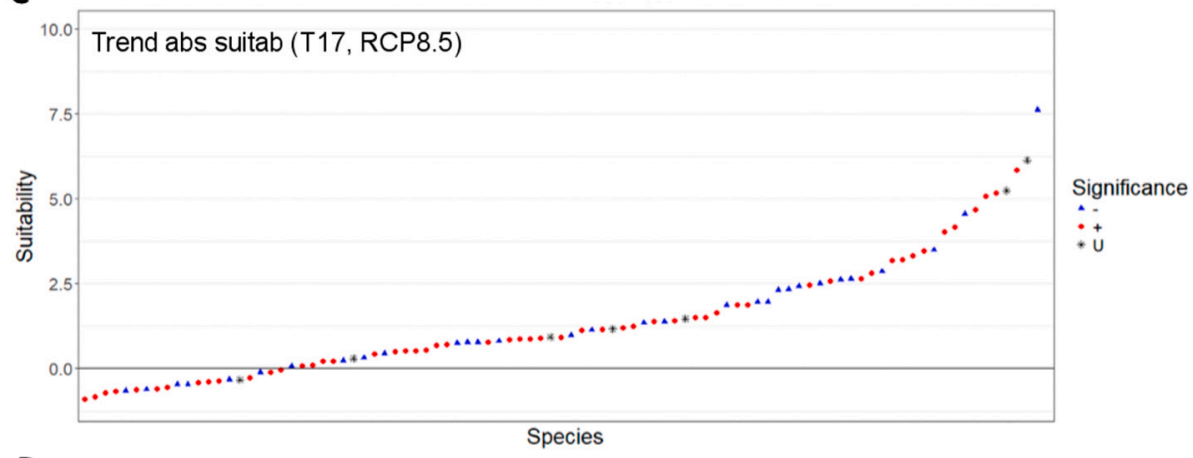

D

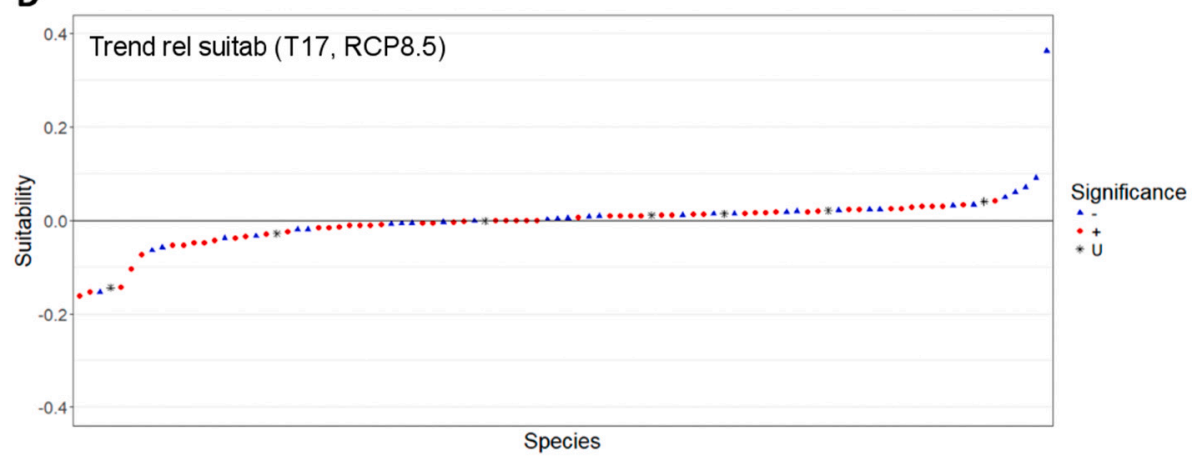

Fig. 3. Trends in absolute suitability (A \& C) and relative suitability scores (B \& D) for each species in established PAs and T17 using RCP8.5 scenario. We assume results as significant by comparing them with measurements in random area sets of similar size, such that, significantly lower or higher values were obtained after comparing with the $5 \%$ minor $(-)$ and top scores $(+)$, respectively. $U$ for no significant scores. The $\mathrm{x}$-axis refers to species, ordered from the lowest to the highest suitability values. respond to present-day disturbances. However, two factors make that assertion flawed: (a) the current rates of climate change seem to be much larger than in the past (Pecl et al., 2017) and (b) since the European colonization and especially in the last century, expanding and overintensive land uses have resulted in increased habitat fragmentation and increased resistance of landscapes to the natural accommodations of species ranges to suitable climates (Pereira et al., 2010). Moreover, following the worldwide context, governments in the CM have been settling ePAs to accomplish only the quantitative goals established under the CBD's 11th Aichi Target, forgetting to include the very critical aspect of "effectively and equitably managed, ecologically representative and well-connected systems of PAs and other effective area-based conservation measures". In this context, several studies have focused on the responses of distinct species groups to recent climate change in Mexico (Peterson et al., 2011). Others have analysed the extent to which climate change will undermine ePAs in covering species' ranges (Botello et al., 2018). However, no compressive study has assessed conjunctly: (a) the fraction of ePAs that still promote species persistence at longterm; (b) the performance of ePAs in securing suitable climatic and land conditions (against the more typical assessments using binary 
species' occurrence data) and, (c) which areas deliver complementary value to ePAs, such that a new PA network is established with the less cost, the highest robustness and the highest effectiveness in capturing species suitable areas at medium to long-terms.

Our results deliver an optimistic overview about the functionality of ePAs in CM, as a great amount of ePAs (61\%) are located in regions depicted as top-priority from several optimised setups of top priority areas (T17). Importantly, we also found that results were largely robust to the uncertainties derived from: (a) unknown future environmental trajectories (i.e. climate and land-use); (b) two plausible assumptions about species' dispersal capabilities, and, (c) the operational choices about the relative effort to put in the protection of each species, comparatively to the competing species.

Various studies have found that distinct future climate trajectories impact PA-effectiveness at different extents. For example, Wintle et al. (2011); McCarthy et al. (2012) and Shaw et al. (2012) show that differences in PA-effectiveness from the worst case to the most benign scenarios may be significant and may largely differ on the financial resources required. To circumvent such flaws, the surpluses efforts required to establish monitoring studies and to settle flexible and adaptive management schemes may still result cheaper compared with inaccurate, fixed plans, deterministically designed for a single scenario (Polasky et al., 2011).

Similarly, species dispersal capacity (i.e., dispersal rate and dispersal habitat affinity) is a key determinant of the success of species in following their shifting suitable climate regions (Kokko and LópezSepulcre, 2006). The mechanisms beyond climate-adaptive dispersal emerge from metapopulation dynamics at species' range edges (Anderson et al., 2009) and, therefore, are deeply contextual, because local patterns of habitat fragmentation and disturbance drive the success of individuals and population flows among suitable habitat patches. These specificities are not able to be fully integrated in studies undertaken at larger, biogeographical scales. Consequently, credible generalisations on the spatial ecology of metapopulations along the whole species ranges need to be made, while detailed data are not available.

Finally, each single species presents distinct roles within the various ecosystems in which it occurs (Coux et al., 2016). Depending on the cooccurring species, their abundances and the structure of communities, a species may be trophically, functionally or phylogenetically redundant in one area and irreplaceable in other. This contextual ecological significance of a species along distinct environmental regimes and its conservation status turn complex, and subjective, the definition of the species (or species pools) to prioritise for protection (Alagador and Cerdeira, 2019). Under low-limiting financial scenarios and when multiple species require very specific assistance, triage might be an inevitable decision to make (Bottrill et al., 2009; Gilbert et al., 2020).

In this study, we have provided a controlled analysis on the uncertainty characterizing distinct processes (i.e., variability of BNM outputs, the future climatic and land-use storylines, species dispersal rates and species-weighting). Establishing robustness as a strategic property of forward-looking conservation plans, delivers planners and decisionmakers the confidence and momentum to actively proceed in the allocation of financial resources for the establishment of PAs and for the design and implementation of monitoring and flexible management plans (Ando and Hannah, 2011). Moreover, whatever the robustness imprinted in planning process, planners need to accept the possibility of readapting their plans to unexpected occurrences, so to conservation succeed at long-term.

Every study relying on anticipative and predictive techniques and on a particular set of species does naturally carry some flaws. This research is not an exception. First, the 94 species analysed, although listed in the regional conservation plans as conservation priorities, are still a small component of the biodiversity of a biodiversity-rich zone. With data available, other species could be also integrated for a comprehensive overview of the spatial conservation priorities in the study area. Second, BNMs tend to be accurate in expressing the spatial patterns of most species at broad spatial scales (Pearson et al., 2004; Araujo and Guisan, 2006), however at finer scales there are other factors that determine the occurrence of a species. Species interactions (Araújo and Luoto, 2007; Araújo and Rozenfeld, 2014), population processes (Fordham et al., 2013), spatial patterns of suitable habitats (Hanski and Ovaskainen, 2000), specific small-scale anthropic threats (Araújo et al., 2008) and micro-scaled topographic and climate features (Hannah et al., 2014) are examples of such processes that need to be integrated in subsequent stages of conservation plans (i.e., when opportunities and specificities within the areas primarily highlighted are assessed - see below for a short description). Third, an important limitation of this analysis resides in the coarse temporal resolution of data (i.e., 30 years) which, under dynamic contexts, may preclude the identification of continuouslychanging trajectories of priority areas that may assist the precise scheduling of actions along time. Fine grained-temporal quality data reporting on past, present and future climate are hard to get and when existing, may require important computational resources to analyse.

The regional solutions here proposed should be taken as a first stage of a nested hierarchical planning strategy. The regions highlighted at an upper-level scale need to be appraised in more detail, using more resolute data. At this level, more specific analyses on habitat availability and socio-environmental factors are required, such that the areas that offer the best adaptive potential for species to be fixed, or move along, are protected and/or restored (Shoo et al., 2013). For example, Alagador et al. (2014) and Alagador and Cerdeira (2020) have introduced a set of models to obtain the trajectories that species are more likely to follow, given the directionality of drivers of change at multiple scales. These trajectories define full conservation units where species are able to persist through either local adaptation or adaptive movements along suitable areas, and therefore may give rise to core zones of PAs or transitional areas to protect in a less formal and permanent manner. Importantly, using changing socio-economic values of the areas that define trajectories, the solutions so obtained contribute for minimising conflicts between agents with presumably competing interests (e.g. conservationists versus land-users) (Green et al., 2018), thus favouring their establishment on the ground and avert area prioritisation where conflicts are expected to be the largest (Nori et al., 2016; Van Vleet et al., 2016; Rodríguez-Soto et al., 2017). Where land-markets are fully operational offering a set of land tenure regimes (full property, rentals, regulatory land-uses, easements, compensatory measures, etc.) the location of PAs may be flexible and dynamic. As more precise climatechange scenarios become available and new evaluations are made on the cost-benefit of ePAs, their temporary or perpetual release from conservation focus may be preferential, if the efforts saved therefore are directed to the protection of the best-valued available areas (Fuller et al., 2010; Alagador et al., 2014). Similarly, the asynchronous and differential responses of species to climate change imply that investments are scheduled in advance, such that financial resources are used in the targeted areas at the right periods and before habitats are irreversible disturbed (Hole et al., 2011; Albers et al., 2017). Ideally, some of these areas should be formalised as PAs, especially when species of large conservation relevance (i.e., endemic, highly threatened, large climate sensitivity) are present (Illoldi-Rangel et al., 2008; Botello et al., 2015). Where the more adaptable species are (or are expected to be) present mild protection regulation may be assigned, such that environmentalfriendly land-uses (e.g., agri-environmental schemes) may still allow the retention and $\backslash$ or reinforcement of adaptive species movements (Kallimanis et al., 2015).

Recently, a partnership called "Mexico Resiliente Alliance" has been launched for the whole country to provide stakeholders coordination schemes and guidance on the actions to take to counteract the negative effects of climate and land use changes (Azuz-Adeath and Cuevas Corona, 2018). The present study provides a benchmark for this initiative quick-start providing guidance at the scale of CM using: (a) a transparent and replicable conservation planning approach; (b) an anticipative and forward looking evaluation on possible ecological 
scenarios for the region and, (c) robustness analyses to control the various uncertain properties of the conservation system analysed. The results should be considered a first approximation to highlight the ePAs where conservation efforts need to be maintained (or boosted) and the new regions likely to deliver the highest effectiveness for an extended, flexible PA network to counteract the negative effects of global changes. At a time at which the global environmental agenda (Desa, 2016) calls governments for quick and wise actions, new analytic frameworks to guide the "where's", "when's" and "how's" of conservation investment are required. We believe that the present study has potential to deliver such guidance for the long-term preservation of an important speciesrich region in Mexico.

\section{CRediT authorship contribution statement}

FCP: formal analysis, visualization, writing-original draft.

CRS: writing-review and editing.

APCR: writing-review and editing.

JCCM: resources;

DA: conceptualization, methodology, writing original draft, supervision.

\section{Declaration of competing interest}

The authors declare that they have no known competing financial interests or personal relationships that could have appeared to influence the work reported in this paper. The work is all original research carried out by the authors and the manuscript is not being considered for publication elsewhere while it is being considered for publication in this journal.

\section{Acknowledgements}

This work was funded by national funds through the Fundação para a Ciência e a Tecnologia (FCT) under the project UIDB/05183/2020 and also by FEDER funds and Programa Operacional Factores de Competitividade - COMPETE - through FCT's project PTDC/AAG-GLO/ 3979/2014 (ref. 9471-RIDTI). The authors have no conflict of interests to declare and are thankful by the contributions of a proficient reviewer.

\section{Appendix A. Supplementary data}

Supplementary data to this article can be found online at https://doi. org/10.1016/j.biocon.2021.109186.

\section{References}

Ackerly DD, Loarie SR, Cornwell WK, Weiss SB, Hamilton H, Branciforte R, Kraft NJB (2010) The geography of climate change: implications for conservation biogeography. Divers. Distrib. 16: 476-487.

Alagador D (2021) New Paradigms for Modern Biogeography Conservation.

Alagador, D., Cerdeira, J.O., 2007. Designing spatially-explicit reserve networks in the presence of mandatory sites. Biol. Conserv. 137, 254-262.

Alagador, D., Cerdeira, J.O., 2019. Introducing spatio-temporal conservation units: models for flexible optimization of species persistence under climate change. In: Handbook of Climate Change and Biodiversity. Springer, pp. 243-258.

Alagador, D., Cerdeira, J.O., 2020. Revisiting the minimum set cover, the maximal coverage problems and a maximum benefit area selection problem to make climatechange-concerned conservation plans effective. Methods Ecol. Evol. 11, 1325-1337.

Alagador, D., Cerdeira, J.O., Araújo, M.B., 2014. Shifting protected areas: scheduling spatial priorities under climate change. J. Appl. Ecol. 51, 703-713.

Albers, H., Maloney, M., Robinson, E., 2017. Economics in systematic conservation planning for lower-income countries: a literature review and assessment. Int. Rev. Environ. Resour. Econ. 10, 145-182.

Allouche, O., Tsoar, A., Kadmon, R., 2006. Assessing the accuracy of species distribution models: prevalence, kappa and the true skill statistic (TSS). J. Appl. Ecol. 43, 1223-1232.

Anderson, B., Akçakaya, H., Araújo, M., Fordham, D., Martinez-Meyer, E., Thuiller, W. Brook, B., 2009. Dynamics of range margins for metapopulations under climate change. Proc. R. Soc. B Biol. Sci. 276, 1415-1420.

Ando, A.W., Hannah, L., 2011. Lessons from finance for new land-conservation strategies given climate-change uncertainty. Conserv. Biol. 25, 412-414.
Araujo, M.B., Guisan, A., 2006. Five (or so) challenges for species distribution modelling. J. Biogeogr. 33, 1677-1688.

Araújo, M.B., Luoto, M., 2007. The importance of biotic interactions for modelling species distributions under climate change. Glob. Ecol. Biogeogr. 16, 743-753.

Araújo, M.B., New, M., 2007. Ensemble forecasting of species distributions. Trends Ecol, Evol. 22, 42-47.

Araújo, M.B., Rozenfeld, A., 2014. The geographic scaling of biotic interactions. Ecography 37, 406-415.

Araújo, M.B., Cabeza, M., Thuiller, W., Hannah, L., Williams, P.H., 2004. Would climate change drive species out of reserves? An assessment of existing reserve-selection methods. Glob. Chang. Biol. 10, 1618-1626.

Araújo, M., Nogués-Bravo, D., Reginster, I., Rounsevell, M., Whittaker, R., 2008. Exposure of European biodiversity to changes in human-induced pressures. Environ. Sci. Pol. 11, 38-45.

Araújo, M.B., Alagador, D., Cabeza, M., Nogués-Bravo, D., Thuiller, W., 2011. Climate change threatens European conservation areas. Ecol. Lett. 14, 484-492.

Azuz-Adeath, I., Cuevas Corona, A., 2018. Mexican Natural Resources Management and Biodiversity Conservation. Springer.

Baldi, G., Texeira, M., Martin, O.A., Grau, H.R., Jobbágy, E.G., 2017. Opportunities drive the global distribution of protected areas. PeerJ 5, e2989.

Barbet-Massin, M., Jiguet, F., Albert, C.H., Thuiller, W., 2012. Selecting pseudo-absences for species distribution models: how, where and how many? Methods Ecol. Evol. 3, $327-338$.

Beaumont, N., Dredge, D., 2010. Local tourism governance: a comparison of three network approaches. J. Sustain. Tour. 18, 7-28.

Bernstein, L., Bosch, P., Canziani, O., Chen, Z., Christ, R., Riahi, K., 2008. IPCC, 2007: climate change 2007. Synthesis Report.

Berteaux, D., Ricard, M., St-Laurent, M.-H., Casajus, N., Périé, C., Beauregard, F., de Blois, S., 2018. Northern protected areas will become important refuges for biodiversity tracking suitable climates. Sci. Rep. 8, 4623.

Botello, F., Sarkar, S., Sánchez-Cordero, V., 2015. Impact of habitat loss on distributions of terrestrial vertebrates in a high-biodiversity region in Mexico. Biol. Conserv. 184, 59-65.

Botello F, Sánchez-Cordero V, Pérez-Cirera V, Villaseñor E, Escobar N, Rhodes A, Vidal O, et al. (2018) Designing Optimal Conservation Area Networks Under Climate Change in Mexico.

Bottrill, M.C., Joseph, L.N., Carwardine, J., Bode, M., Cook, C., Game, E.T., Grantham, H., et al., 2009. Finite conservation funds mean triage is unavoidable. Trends Ecol. Evol. 24, 183-184.

Brooks, T.M., Mittermeier, R.A., da Fonseca, G.A.B., Gerlach, J., Hoffmann, M. Lamoreux, J.F., Mittermeier, C.G., et al., 2006. Global biodiversity conservation priorities. Science 313, 58-61.

Ceballos, G., 2008. Naturaleza Mexicana: Legado de Conservación, 303 pages.

Calcagno, V., de Mazancourt, C., 2010. Glmulti: an R package for easy automated model selection with (generalized) linear models. J. Stat. Softw. 34, 1-29.

Cantu, C., Wright, R.G., Scott, J.M., Strand, E., 2004a. Assessment of current and proposed nature reserves of Mexico based on their capacity to protect geophysical features and biodiversity. Biol. Conserv. 115, 411-417.

Cantu, S., Wright, R.G., Scott, J.M., Strand, E., 2004b. Assessing biodiversity in Nuevo Leon, Mexico: are nature reserves the answer? Nat. Areas J. 24, 150-153.

Ceballos, G., Díaz-Pardo, E., Espinosa, H., Flores-Villela, O., García, A., Martínez, L., Martínez-Meyer, E., et al., 2009. Zonas críticas y de alto riesgo para la conservación de la biodiversidad de México. Capital Natural de México 2, 575-600.

Coad, L., Watson, J.E., Geldmann, J., Burgess, N.D., Leverington, F., Hockings, M., Knights, K., et al., 2019. Widespread shortfalls in protected area resourcing undermine efforts to conserve biodiversity. Front. Ecol. Environ. 17, 259-264.

Costello, C., Polasky, S., 2004. Dynamic reserve site selection. Resour. Energy Econ. 26, 157-174.

Coux, C., Rader, R., Bartomeus, I., Tylianakis, J.M., 2016. Linking species functional roles to their network roles. Ecol. Lett. 19, 762-770.

Cuervo-Robayo, A.P., Téllez-Valdés, O., Gómez-Albores, M.A., Venegas-Barrera, C.S., Manjarrez, J., Martínez-Meyer, E., 2014. An update of high-resolution monthly climate surfaces for Mexico. Int. J. Climatol. 34, 2427-2437.

Desa U (2016) Transforming our World: The 2030 Agenda for Sustainable Development.

Durán, E., Bray, D.B., Velázquez, A., Larrazábal, A., 2011. Multi-scale forest governance, deforestation, and violence in two regions of Guerrero, Mexico. World Dev. 39, 611-619.

Escalante, T., Rodríguez, G., Morrone, J.J., 2004. The diversification of Nearctic mammals in the Mexican transition zone. Biol. J. Linn. Soc. 83, 327-339.

Esperon-Rodriguez, M., Beaumont, L.J., Lenoir, J., Baumgartner, J.B., McGowan, J., Correa-Metrio, A., Camac, J.S., 2019. Climate change threatens the most biodiverse regions of Mexico. Biol. Conserv. 240, 108215.

Faleiro, F.V., Machado, R.B., Loyola, R.D., 2013. Defining spatial conservation priorities in the face of land-use and climate change. Biol. Conserv. 158, 248-257.

Fordham, D.A., Akçakaya, H., Brook, B.W., Rodríguez, A., Alves, P.C., Civantos, E. Trivino, M., et al., 2013. Adapted conservation measures are required to save the Iberian lynx in a changing climate. Nat. Clim. Chang. 3, 899-903.

Franklin, J., 2010. Mapping Species Distributions: Spatial Inference and Prediction. Cambridge University Press, Cambridge \& New Yor, USA, p. 331.

Fuller, T., Sanchez-Cordero, V., Illoldi-Rangel, P., Linaje, M., Sarkar, S., 2007. The cost of postponing biodiversity conservation in Mexico. Biol. Conserv. 134, 593-600.

Fuller, R.A., McDonald-Madden, E., Wilson, K.A., Carwardine, J., Grantham, H.S., Watson, J.E.M., Klein, C.J., et al., 2010. Replacing underperforming protected areas achieves better conservation outcomes. Nature 466, 365.

GA U, 2015. Transforming our World: The 2030 Agenda for Sustainable Development Division for Sustainable Development Goals, New York, NY, USA. 
Gaston, K.J., Jackson, S.F., Cantú-Salazar, L., Cruz-Piñón, G., 2008. The ecological performance of protected areas. Annu. Rev. Ecol. Evol. Syst. 39, 93-113.

GBIF GBIF, 2016. Biodiversity occurrence data provided, accessed through GBIF data portal. http://www.gbif.org.

Geldmann, J., Manica, A., Burgess, N.D., Coad, L., Balmford, A., 2019. A global-level assessment of the effectiveness of protected areas at resisting anthropogenic pressures. Proc. Natl. Acad. Sci. 116, 23209-23215.

Gilbert, S.L., Broadley, K., Doran-Myers, D., Droghini, A., Haines, J.A., Hämäläinen, A., Lamb, C.T., et al., 2020. Conservation triage at the trailing edge of climate envelopes. Conserv. Biol. 34, 289-292.

Gillingham, P.K., Bradbury, R.B., Roy, D.B., Anderson, B.J., Baxter, J.M., Bourn, N.A.D. Crick, H.Q.P., et al., 2015. The effectiveness of protected areas in the conservation of species with changing geographical ranges. Biol. J. Linn. Soc. 115, 707-717.

Green, J.M., Fisher, B., Green, R.E., Makero, J., Platts, P.J., Robert, N., Schaafsma, M., et al., 2018. Local costs of conservation exceed those borne by the global majority. Global Ecol. Conserv. 14, e00385.

Gstaettner, A.M., Kobryn, H.T., Rodger, K., Phillips, M., Lee, D., 2018. Monitoring visitor injury in protected areas-analysis of incident reporting in two western Australian parks. J. Outdoor Recreat. Tour. 25, 143-157.

Hamer, K.C., Newton, R.J., Edwards, F.A., Benedick, S., Bottrell, S.H., Edwards, D.P., 2015. Impacts of selective logging on insectivorous birds in Borneo: the importance of trophic position, body size and foraging height. Biol. Conserv. 188, 82-88.

Hannah, L., 2008. Protected Areas and Climate Change, 1134. Annals of the New York Academy of Sciences, pp. 201-212.

Hannah, L., Midgley, G.F., Millar, D., 2002. Climate change-integrated conservation strategies. Glob. Ecol. Biogeogr. 11, 485-495.

Hannah, L., Flint, L., Syphard, A.D., Moritz, M.A., Buckley, L.B., McCullough, I.M., 2014 Fine-grain modeling of species' response to climate change: holdouts, steppingstones, and microrefugia. Trends Ecol. Evol. 29, 390-397.

Hanski, I., Ovaskainen, O., 2000. The metapopulation capacity of a fragmented landscape. Nature 404, 755-758.

Hart, A., 2001. Mann-Whitney test is not just a test of medians: differences in spread can be important. BMJ: Br. Med. J. 323, 391.

Hijmans, R.J., Cameron, S.E., Parra, J.L., Jones, P.G., Jarvis, A., 2005. Very high resolution interpolated climate surfaces for global land areas. Int. J. Climatol. 25, 1965-1978.

Hole, D.G., Huntley, B., Arinaitwe, J., Butchart, S.H., Collingham, Y.C., Fishpool, L.D., Pain, D.J., et al., 2011. Toward a management framework for networks of protected areas in the face of climate change. Conserv. Biol. 25, 305-315.

Illoldi-Rangel, P., Fuller, T., Linaje, M., Pappas, C., Sánchez-Cordero, V., Sarkar, S., 2008. Solving the maximum representation problem to prioritize areas for the conservation of terrestrial mammals at risk in Oaxaca. Divers. Distrib. 14, 493-508.

Inegi. (2013) Conjunto de datos vectoriales de uso del suelo y vegetación, escala 1: 250 000, Serie V. Mapa. In: Inegi Cd. de México.

Injeti, S.K., Kumar, N.P., 2013. A novel approach to identify optimal access point and capacity of multiple DGs in a small, medium and large scale radial distribution systems. Int. J. Electr. Power Energy Syst. 45, 142-151.

Johnston, A., Ausden, M., Dodd, A.M., Bradbury, R.B., Chamberlain, D.E., Jiguet, F., Thomas, C.D., et al., 2013. Observed and predicted effects of climate change on species abundance in protected areas. Nat.Clim. Change 3, 1055-1061.

Johnstone, J.F., Allen, C.D., Franklin, J.F., Frelich, L.E., Harvey, B.J., Higuera, P.E., Mack, M.C., et al., 2016. Changing disturbance regimes, ecological memory, and forest resilience. Front. Ecol. Environ. 14, 369-378.

Joppa, L.N., Pfaff, A., 2009. High and far: biases in the location of protected areas. PLoS One 4, e8273.

Juffe-Bignoli D, Burgess N, Bingham H, Belle E, Lima M, Deguignet M, Bertzky B, et al. (2014) Protected Planet Report 2014.

Kallimanis, A.S., Touloumis, K., Tzanopoulos, J., Mazaris, A.D., Apostolopoulou, E., Stefanidou, S., Scott, A.V., et al., 2015. Vegetation coverage change in the EU: patterns inside and outside Natura 2000 protected areas. Biodivers. Conserv. 24, 579-591.

Kokko, H., López-Sepulcre, A., 2006. From individual dispersal to species ranges: perspectives for a changing world. Science 313, 789-791.

Le Saout, S., Hoffmann, M., Shi, Y., Hughes, A., Bernard, C., Brooks, T.M., Bertzky, B., et al., 2013. Protected areas and effective biodiversity conservation. Science 342, 803-805.

Leach, K., Zalat, S., Gilbert, F., 2013. Egypt's protected area network under future climate change. Biol. Conserv. 159, 490-500.

Leadley, P.W., Krug, C.B., Alkemade, R., Pereira, H.M., Sumaila, U.R., Walpole, M., Marques, A., Newbold, T., Teh, L.S.L, van Kolck, J., Bellard, C., JanuchowskiHartley, S.R., Mumby, P.J., 2014. Progress towards the Aichi Biodiversity Targets: An Assessment of Biodiversity Trends, Policy Scenarios and Key Actions, 78. Secretariat of the Convention on Biological Diversity, Montreal, Canada, p. 500. Technical Series.

Loucks, C., Ricketts, T.H., Naidoo, R., Lamoreux, J., Hoekstra, J., 2008. Explaining the global pattern of protected area coverage: relative importance of vertebrate biodiversity, human activities and agricultural suitability. J. Biogeogr. 35, 1337-1348.

Loyola, R.D., Lemes, P., Brum, F.T., Provete, D.B., Duarte, L.D.S., 2014. Clade-specific consequences of climate change to amphibians in Atlantic Forest protected areas. Ecography 37, 65-72.

Margules, C.R., Pressey, R.L., 2000. Systematic conservation planning. Nature 405, 243-253.

McCarthy MA, Possingham HP (2007) Active Adaptive Management for Conservation Manejo Adaptativo Activo para Conservar. Conserv. Biol. 21: 956-963.
McCarthy, D.P., Donald, P.F., Scharlemann, J.P., Buchanan, G.M., Balmford, A., Green, J. M., Bennun, L.A., et al., 2012. Financial costs of meeting global biodiversity conservation targets: current spending and unmet needs. Science 338, 946-949.

Merow, C., Smith, M.J., Edwards Jr., T.C., Guisan, A., McMahon, S.M., Normand, S., Thuiller, W., et al., 2014. What do we gain from simplicity versus complexity in species distribution models? Ecography 37, 1267-1281.

Michalak, J.L., Lawler, J.J., Roberts, D.R., Carroll, C., 2018. Distribution and protection of climatic refugia in North America. In: Conservation Biology.

Moilanen, A., Pouzols, F., Meller, L., Veach, V., Arponen, A., Leppänen, J., Kujala, H., 2014. Zonation Version 4 User Manual. C-BIG Conservation Biology Informatics Group, Department of Biosciences, University of Helsinki, Helsinki, p. 12.

Moreno-Barajas, R., Talavera-Garduño, K., Rivera-Morales, S., Hernández-Ramírez, N., 2019. Evaluation of the current situation of the natural protected areas of the state of Mexico. Quivera: Revista de Estudios Territoriales 21, 113-119.

Morrone, J.J., Escalante, T., Rodriguez-Tapia, G., 2017. Mexican biogeographic provinces: map and shapefiles. Zootaxa 4277, 277-279.

Nori, J., Torres, R., Lescano, J.N., Cordier, J.M., Periago, M.E., Baldo, D., 2016. Protected areas and spatial conservation priorities for endemic vertebrates of the Gran Chaco, one of the most threatened ecoregions of the world. Divers. Distrib. 22, 1212-1219.

Ortega Huerta, M.A., 2007. Fragmentation patterns and implications for biodiversity conservation in three biosphere reserves and surrounding regional environments, northeastern Mexico. Biol. Conserv. 134, 83-95.

Pearson, R.G., Dawson, T.P., Liu, C., 2004. Modelling species distributions in Britain: a hierarchical integration of climate and land-cover data. Ecography 27, 285-298.

Pecl, G.T., Araújo, M.B., Bell, J.D., Blanchard, J., Bonebrake, T.C., Chen, I.-C., Clark, T. D., et al., 2017. Biodiversity redistribution under climate change: impacts on ecosystems and human well-being. Science 355.

Pelegrin J, Gamboa S, Menéndez I, Hernández Fernández M (2018) The Great American Biotic Interchange: A Paleoecological Review Considering Neotropical Mammals and Birds.

Pereira, H.M., Leadley, P.W., Proença, V., Alkemade, R., Scharlemann, J.P., FernandezManjarrés, J.F., Araújo, M.B., et al., 2010. Scenarios for global biodiversity in the 21st century. Science 330, 1496-1501.

Peterson, A.T., Soberón, J., Pearson, R.G., Anderson, R.P., Nakamura, M., MartinezMeyer, E., Araújo, M.B., 2011. Ecological Niches and Geographical Distributions. Princeton University Press, New Jersey.

Polasky, S., Carpenter, S.R., Folke, C., Keeler, B., 2011. Decision-making under great uncertainty: environmental management in an era of global change. Trends Ecol. Evol. 26, 398-404.

Rodríguez-Soto, C., Velazquez, A., Monroy-Vilchis, O., Lemes, P., Loyola, R., 2017. Joint ecological, geographical and cultural approach to identify territories of opportunity for large vertebrates conservation in Mexico. Biodivers. Conserv. 1-20.

Rojas, M., 1992. The species problem and conservation: what are we protecting? Conserv. Biol. 6, 170-178.

Schubert, B.W., Chatters, J.C., Arroyo-Cabrales, J., Samuels, J.X., Soibelzon, L.H., Prevosti, F.J., Widga, C., et al., 2019. Yucatán carnivorans shed light on the great American biotic interchange. Biol. Lett. 15, 20190148.

SEMARNAT, 2010. In: SdMAyR eNaturales (Ed.), NOM-059-ECOL-SEMARNAT-2010. Diario Oficial de la Federación. Norma Oficial Mexicana, pp. 1-86.

Shaw, M.R., Klausmeyer, K., Cameron, D.R., Mackenzie, J., Roehrdanz, P., 2012. Economic costs of achieving current conservation goals in the future as climate changes. Conserv. Biol. 26, 385-396.

Shoo, L.P., Hoffmann, A.A., Garnett, S., Pressey, R.L., Williams, Y.M., Taylor, M., Falconi, L., et al., 2013. Making decisions to conserve species under climate change. Clim. Chang. 119, 239-246.

Sieck, M., Ibisch, P.L., Moloney, K.A., Jeltsch, F., 2011. Current models broadly neglect specific needs of biodiversity conservation in protected areas under climate change. BMC Ecol. 11, 12.

Strange, N., Thorsen, B.J., Bladt, J., 2006. Optimal reserve selection in a dynamic world. Biol. Conserv. 131, 33-41.

Thomas, C.D., Gillingham, P.K., 2015. The performance of protected areas for biodiversity under climate change. Biol. J. Linn. Soc. 115, 718-730.

Thuiller, W., Georges, D., Engler, R., Breiner, F., Georges, M.D., Thuiller, C.W., 2016. Package 'biomod2'.

Tittensor, D.P., Walpole, M., Hill, S.L.L., Boyce, D.G., Britten, G.L., Burgess, N.D., Butchart, S.H.M., et al., 2014. A mid-term analysis of progress toward international biodiversity targets. Science 346, 241-244.

Van Vleet, E., Bray, D.B., Durán, E., 2016. Knowing but not knowing: systematic conservation planning and community conservation in the Sierra Norte of Oaxaca, Mexico. Land Use Policy 59, 504-515.

Warren, R., VanDerWal, J., Price, J., Welbergen, J.A., Atkinson, I., Ramirez-Villegas, J., Osborn, T.J., et al., 2013. Quantifying the benefit of early climate change mitigation in avoiding biodiversity loss. Nat. Clim. Chang. 3, 678-682.

Wintle, B.A., Bekessy, S.A., Keith, D.A., Van Wilgen, B.W., Cabeza, M., Schröder, B., Carvalho, S.B., et al., 2011. Ecological-economic optimization of biodiversity conservation under climate change. Nat. Clim. Chang. 1, 355-359.

Woodley, S., Bertzky, B., Crawhall, N., Dudley, N., Londoño, J.M., MacKinnon, K., Redford, K., et al., 2012. Meeting Aichi target 11: what does success look like for protected area systems. Parks 18, 23-36.

Zhu, M.-J., Hoctor, T.S., Volk, M., Frank, K.I., Zwick, P.D., Carr, M.H., Linhoss, A.C., 2015. Spatial conservation prioritization to conserve biodiversity in response to sea level rise and land use change in the Matanzas River basin, Northeast Florida. Landsc. Urban Plan. 144, 103-118. 